\title{
FATORES DESENCADEADORES DE MOVIMENTOS DE MASSA NO MACIÇO DE MARANGUAPE, CEARÁ, BRASIL
}

\author{
Gilney Monteiro Barbosa ${ }^{(a)}$, Frederico de Holanda Bastos ${ }^{(b)}$, Adisson Souza Tavares ${ }^{(\mathrm{c})}$, Yuri da \\ Silva Belarmino ${ }^{(\mathrm{d})}$
}

(a) Curso de Geografia / Licenciatura, Universidade Estadual do Ceará, Gilneybarbosa@ hotmail.com

(b) Professor doutor adjunto do curso de Geografia, Universidade Estadual do Ceará, fred_holanda@yahoo.com.br

(c) Curso de Geografia / Bacharelado, Universidade Estadual do Ceará, adisson.souza @ aluno.uece.br

(d) Curso de Geografia / Licenciatura, Universidade Estadual do Ceará, yuri.belarmino@ @aluno.uece.br

\section{Eixo: GEOGRAFIA FÍSICA E DESASTRES NATURAIS}

\begin{abstract}
Resumo
O presente trabalho visa apontar fatores desencadeadores de movimentos gravitacionais de massa, traçando uma relação entre os componentes geoambientais e setores susceptíveis à ocorrência de tais processos, tendo como recorte espacial a serra de Maranguape. Este maciço é considerado um ambiente de exceção no semiárido, apresentando elevados índices pluviométricos, além de clima, solo, vegetação e relevo diferenciados de seu entorno. Nas vertentes, ocorrem os relevos mais dissecados, sendo a vertente oriental úmida onde se concentram os maiores totais pluviométricos. Verifica-se que nestas áreas de alta pluviosidade e relevos dissecados há forte susceptibilidade ao desencadeamento de movimentos gravitacionais de massa que, junto à ação antropogênica, podem ser acelerados e intensificados, sendo que deslizamentos e fluxos de lama são os exemplos mais comuns. Este estudo sobre movimentos de massa e dinâmica das vertentes pode auxiliar em futuros trabalhos de cunho ambiental, como o planejamento e ordenamento territorial.
\end{abstract}

Palavras chave: Serras úmidas cearenses; Morfodinâmica; Perigo geológico.

\section{Introdução}

O maciço de Maranguape está inserido na Região Metropolitana de Fortaleza (RMF), a uma distância de $28 \mathrm{~km}$ da capital, sendo considerado ambiente de exceção no contexto do semiárido cearense. De acordo com Souza (2011), nas paisagens de exceção do Estado do Ceará, os processos morfodinâmicos estão subordinados intrinsecamente às condições hidroclimáticas, onde sua eficácia é dependente da capacidade protetora da vegetação, topografia do terreno e das formas de uso e ocupação do solo.

A serra de Maranguape (Figura 1) se destaca como um importante maciço pré-litorâneo recoberto por mata úmida, atingindo cotas acima de $900 \mathrm{~m}$ e com um relevo bastante acidentado, apresentando forte instabilidade morfodinâmica associada à elevada capacidade energética dos processos gravitacionais que atuam em suas encostas, podendo ocorrer eventos catastróficos de grande magnitude, com significativos riscos para a população local. 

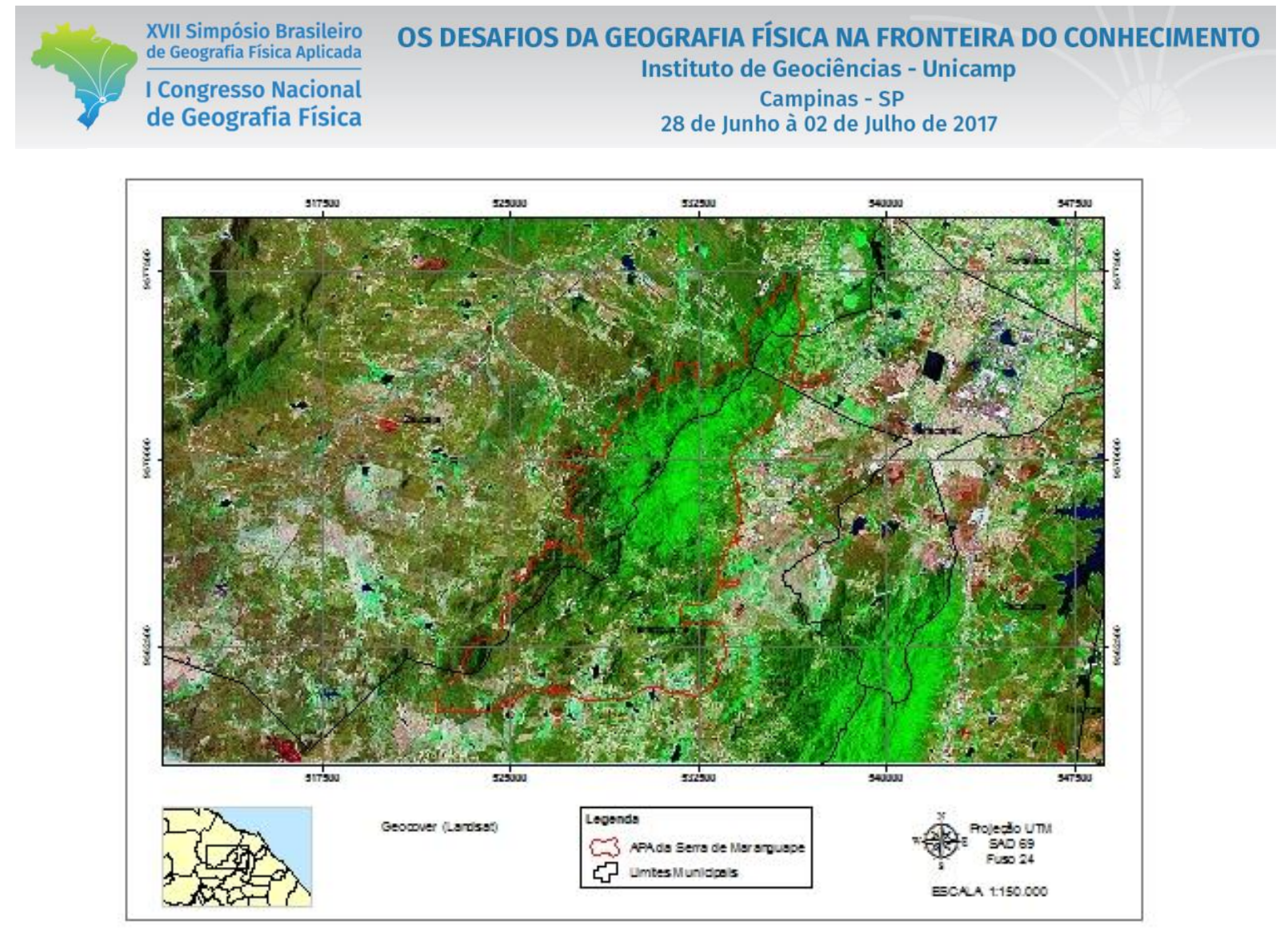

Figura 1: Localização da serra de Maranguape. Fonte: SEMACE (2009).

Face ao exposto, o presente trabalho visa apontar fatores que podem desencadear movimentos gravitacionais de massa na Serra de Maranguape, caracterizando seus componentes geoambientais e mostrando sua influência na configuração da paisagem favorável ao surgimento de tais processos morfodinâmicos.

\section{Metodologia}

Para se alcançar o objetivo deste trabalho foram feitos levantamentos bibliográficos na busca de trabalhos como artigos, monografias, livros, dissertações e teses que tratem do quadro natural dos ambientes cearenses, como Souza $(1988,2006,2011)$. Outras publicações de pesquisas voltadas para os estudos de processos morfodinâmicos foram consultadas, com enfoque para os movimentos de massa como os trabalhos de Dikau (2004) e Bastos (2012), sendo este, referência de pesquisas aplicadas ao Estado do Ceará sobre movimentos de massa em ambientes serranos. A coleta de dados sobre a área de estudo é imprescindível para a formação deste trabalho, onde foram consultadas publicações de pesquisas e de órgãos públicos. 
Os mapas mais consultados para os levantamentos cartográficos foram o Mapa Geológico do Estado do Ceará, elaborado pela CPRM (2003) na escala de 1:500.000, e o Mapa Morfoestrutural do Estado do Ceará e Adjacências na escala de 1:500.000, de autoria de Peulvast e Claudino Sales (2003).

De posse desse material foram realizados trabalhos em campo, na área objeto de estudo, buscando identificar registros de movimentos de massa na paisagem serrana e, por fim, a última etapa se deu através da integralização e interpretação dos dados obtidos no levantamento bibliográfico junto ao levantamento de campo para escrita final do artigo.

\section{Resultados obtidos e discussão}

Os movimentos de massa são, assim como os processos de intemperismo e erosão, fenômenos naturais contínuos de dinâmica extensa, que modelam a paisagem da superfície terrestre (FERNANDES e AMARAL, 2003), resultado do quadro evolutivo das vertentes, responsáveis pela esculturação da paisagem e na maioria das vezes por grandes prejuízos socioeconômicos. Tais movimentos podem ser desencadeados por diversos fatores, como pela influência da "estrutura geológica, do regolito e solos, da geomorfologia e declividade, da pluviosidade, da cobertura vegetal e da ação antrópica” (BASTOS, 2012).

Dikau (2004) divide os movimentos de massa em quedas (falls), tombamentos (topple), deslizamentos (slides) rotacionais e translacionais, espalhamentos laterais (lateral spreading), fluxos ou corridas (flow) e movimentos complexos (complex). No caso específico da serra de Maranguape, constata-se a ocorrência de quedas, deslizamentos, fluxos e movimentos complexos.

A estrutura geológica da área, de acordo com Medeiros et al (1995), é representada pela associação de gnaisses e migmatitos, ocupando cerca de $53 \%$ da área e rochas plutônicas granitóides com cerca de $45 \%$ da área. Logo, as características de fraturas, diaclases, dobramentos e outros elementos, são responsáveis pela coesão do material, sendo este um importante fator no desprendimento de materiais rochosos. O grau de intemperização das rochas vai depender de suas propriedades físico-químicas (BASTOS, 2012) de acordo com as condições climáticas de cada área.

Os solos que predominam na serra de Maranguape são os argissolos vermelhos-amarelo eutróficos, com alto teor de argila no horizonte $\mathrm{B}$, localizados nos setores mais úmidos da serra e de maior altitude que resultam em perfis profundos e muito profundos. Estes solos apresentam significativas diferenças texturais ao longo de seu perfil, o que facilita sua saturação hídrica e ocorrência de deslizamentos e/ou fluxos. Os neossolos litólicos eutróficos completam o quadro de solos do local, com fraca evolução pedológica, rasos e pedregosos, de textura arenosa com forte susceptibilidade à erosão, localizados na vertente seca 


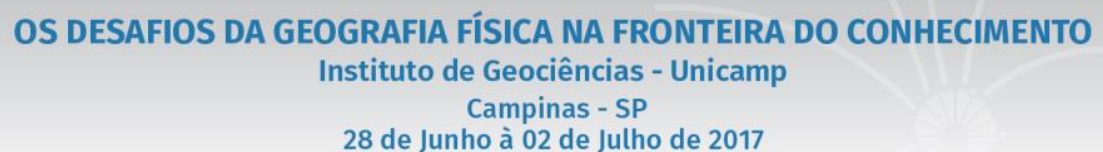

28 de Junho à 02 de Julho de 2017

(CORDEIRO; GARCEZ; BASTOS, 2014). Os movimentos de quedas de blocos se configuram nas áreas de ocorrência desses solos, onde é muito comum a presença de afloramentos.

Os ambientes serranos cearenses apresentam relevo fortemente dissecado, com declives íngremes que podem ultrapassar os $40^{\circ}$. A serra de Maranguape também se insere neste contexto apresentando formas como colinas convexas e vales em forma de "V". Nas vertentes ocorrem as topografias mais acidentadas, sendo a vertente oriental úmida do maciço, onde se concentram as maiores taxas de pluviosidade. Contudo, são nestes locais de alta declividade onde se concentram os maiores índices de movimentos de massa, sendo geralmente entre $37^{\circ}-55^{\circ}$ configurados movimentos de regolito, e acima disto há uma probabilidade maior de eventos de queda de materiais, conforme Bastos (2012) sugeriu para o maciço de Baturité, que se trata de uma ambiente serrano similar à presente área de estudo.

Por estar situado próximo ao litoral, o maciço de Maranguape apresenta índices pluviométricos elevados, com médias anuais de 1.379,9 mm (CEARÁ, 2014). Seu clima sofre influência tanto da altitude, quanto pela proximidade ao mar, justificando a ocorrência significativa de chuvas orográficas. Portanto, por ser um ambiente que recebe grandes volumes de chuvas anuais e concentradas em alguns meses, há grande susceptibilidade aos de fluxos de lama ou deslizamentos de terra pela saturação hídrica do solo, sendo este fator o mais importante desencadeador de processos morfodinâmicos em ambientes tropicais.

Segundo Cordeiro, Garcez e Bastos (2014), o setor úmido deste maciço é recoberto por floresta pluvionebular subperenifólia, diferente do sopé da serra, onde ocorre mata seca semicaducifólia, evidenciando uma transição na paisagem sertaneja (superfícies mais baixas), revestida por diferentes tipos de caatingas e por pequenas manchas de mata ciliar. Percebe-se que existe uma maior degradação da vegetação em vertentes mais secas pelo uso intenso do solo para implantação de culturas agrícolas, diminuindo a estabilidade morfodinâmica das encostas e provocando movimentos de massa.

A degradação da cobertura vegetal provocada pela população modifica o ambiente, trazendo impactos e rupturas do equilíbrio ecológico, formando um meio com ecodinâmica tendendo à instabilidade (TRICART, 1977). Souza (2011) afirma que a bananicultura, que degrada a vegetação natural das serras é possivelmente responsável pelos principais problemas ambientais da serra de Maranguape, entre eles os processos de fluxo de lama.

Além dos problemas citados, constata-se que houve um significativo aumento do processo de especulação imobiliária, induzindo à compra de terrenos e sítios para a construção de residências e casas de veraneio, caracterizando, desse modo, um crescimento dos impactos ambientais. $\mathrm{O}$ desmatamento das áreas de encosta e os cortes de talús, realizados para construção de novas moradias ou estradas, deixam as encostas 
descobertas, além de alterar a geometria das encostas, contribuindo de forma considerável para o aumento do escoamento superficial, aumentando os riscos de movimentos de massa nestas áreas.

\section{Considerações finais}

Os estudos acerca da temática de processos morfodinâmicos são importantes para se compreender a evolução geomorfológica do local, e o porquê da área estar susceptível a movimentos de material na encosta. Dessa forma, o presente trabalho pode despertar o interesse em outros pesquisadores, no intuito de se elaborar estudos mais detalhados sobre movimentos de massa no maciço de Maranguape.

\section{Bibliografia}

BASTOS, F. H.. Movimentos de massa no maciço de Baturité (CE) e contribuições para estratégias de planejamento ambiental. Tese de doutorado apresentado ao Programa de Pós Graduação em Geografia da Universidade Federal do Ceará, 2012. 258p.

CEARÁ. Instituto de Pesquisa e Estratégia Econômica. Perfil básico municipal 2014 Maranguape. Fortaleza: IPECE, 2014. 18p.

CORDEIRO, A. M. N.; GARCEZ, D. S.; BASTOS, F. de H.. A influência dos componentes geoambientais e das intervenções antropogênicas nos movimentos de massa na sub-bacia hidrográfica do rio Pirapora, Maranguape, Ceará. Geografia ensino e pesquisa, 2013, n. 1. Santa Maria: 2014.

DIKAU, R.. In: GOUDIE, A (Hrsg). Encyclopedia of geomorphology. 2004. 644-652 p.

FERNANDES, N. F.; AMARAL, C. P.. Movimentos de massa: uma abordagem geológica-geomorfológica. In CUNHA e GUERRA (Orgs). Geomorfologia e meio ambiente. $1^{\text {a }}$ ed. Rio de Janeiro: Bertrand Brasil, 2003. 123$194 \mathrm{p}$.

PEULVAST, J. P.; CLAUDINO SALES, V. Carta morfoestrutural do Ceará e áreas adjacentes do Rio Grande do Norte e da Paraíba. CPRM, Atlas digital de Geologia e Recursos Minerais do Ceará. Geologia, Recursos Minerais, Geoquímica, Geofísica, Geomorfologia. Sistema de Informações Geográficas-SIG. Edição, 2003.

SOUZA, M. J. N. Contexto ambiental do enclave úmido da serra de Baturité-Ceará. In: BASTOS, F. H. (org.). Serra de Baturité: uma visão integrada das questões ambientais. Fortaleza: Expressão Gráfica e Editora, 2011.

SOUZA, M. J. N. Contribuição ao estudo das unidades morfo-estruturais do Estado do Ceará. Revista de geologia, 1988, n. 01. Fortaleza: 1988. 
SOUZA, M. J. N. de.; OLIVEIRA, V. P. V. de.. Os enclaves úmidos e sub-úmidos do semiárido do nordeste brasileiro. Mercator, 2005, n. 09. Fortaleza: 2006.

TRICART, J. Ecodinâmica. FIBGE - SUPREN, Rio de Janeiro, 1977.

\section{Agradecimentos}

Agradecimentos sejam dados à Universidade Estadual do Ceará (UECE) por fornecer o suporte do ambiente acadêmico, juntamente ao professor Dr. Frederico de Holanda Bastos e ao grupo do Laboratório de Estudos Morfoestruturais e Pedológicos (LEMEP), pelo apoio pessoal e institucional. Também agradeço ao Conselho Nacional de Desenvolvimento Científico e Tecnológico (CNPq) por fomentar a pesquisa de iniciação científica. 